\title{
22
}

\section{Comparison of SWMM4 and SWMM5 Results to Flow Monitoring Data}

\author{
Mi Chen, Benjamin Gamble, Joseph Koran, Ralph \\ Johnstone and Edward Burgess.
}

The Storm Water Management Model (SWMM) Version 5 has recently been released by USEPA. This version is the first major update to SWMM since 1988, and it has generated a high level of interest among the entire SWMM user community. SWMM5 includes a utility program to convert older SWMM format datasets to the new SWMM5 data format, which facilitates migration to the new version. As users test SWMM5 against SWMM4, there can be some discrepancies between the hydrographs generated from the two versions running the same application. This chapter presents a study that (i) compares the hydrographs in terms of flow pattern, peak flow depth/rate, and timing, generated from the two versions to evaluate the compatibility of SWMM4 and SWMM5, and (ii) compares both simulated results to field data to evaluate the accuracy of simulated results from the two versions if a discrepancy exists between two model simulated results. The comparison results indicate that both versions agree with each other and generally match the field data although some differences between simulated and observed data exist.

Chen, M., B. Gamble, J. Koran, R. Johnstone and E. Burgess. 2006. "Comparison of SWMM4 and SWMM5 Results to Flow Monitoring Data." Journal of Water Management Modeling R225-22. doi: 10.14796/JWMM.R225-22.

(C) CHI 2006 www.chijournal.org ISSN: 2292-6062 (Formerly in Intelligent Modeling of Urban Water Systems. ISBN: 0-9736716-2-9) 


\subsection{Introduction}

The Storm Water Management Model (SWMM) Version 5.0.005a (SWMM5) has recently been released by USEPA. This product was developed by the Water Supply and Water Resources Division of the U.S. Environmental Protection Agency's National Risk Management Research Laboratory in a joint development effort with CDM, Inc., a global consulting, engineering, construction, and operations firm. This version is a complete re-write of the previous released versions and the first major update of SWMM (Huber and Dickinson, 1988) since 1988. SWMM5 written in C programming language keeps the fundamental characteristics of the EXTRAN solution and the performance efficiency of SWMM4 while it slightly modified the computational scheme so as to produce more numerically stable solutions in less time (Rossman, 2005).

Both versions of SWMM employ the same explicit finite difference form of the Saint Venant equations that govern dynamic wave flow routing. SWMM5 applies a Successive Approximation method with under-relaxation to solve these equations while SWMM4 uses a modified Euler method. More details on the difference between the solution methods of the two SWMMs can be found in the report Storm Water Management Model Quality Assurance Report: Dynamic Wave Flow Routing (Rossman, 2005).

SWMM5 enhances the ease of model use with a graphical user interface for the Microsoft Windows operating system. With SWMM5 running under Windows, users can edit study area input data, run hydrologic, hydraulic and water quality simulations, and view the results in a variety of formats. The integrated environment of SWMM5 provides new features such as colorcoded drainage area and conveyance system maps, time series graphs and tables, profile plots, and statistical frequency analyses. In addition, SWMM5 includes a utility program to convert older SWMM format datasets to the new SWMM5 data format, which facilitates migration to the new version (Chan et al., 2004). SWMM5 has generated a high level of interest among the entire SWMM user community.

As users tested SWMM5 against SWMM4, there were some discrepancies between the hydrographs generated from the two versions running the same application. In order to better understand these differences in the simulated results and to help modelers evaluate SWMM5 use for research and application, a study was conducted to (i) compare the hydrographs in terms of flow pattern, peak flow depth/rate, and timing, generated from both versions of SWMM to evaluate the compatibility of 
SWMM4 and SWMM5, and (ii) compare both simulated results to field data to evaluate the accuracy of simulated results from both SWMM versions if a significant discrepancy exists between two model simulated results.

\subsection{Experimental Design}

In cooperation with the Metropolitan Sewer District of Greater Cincinnati (MSDGC), data from the completed System Wide Model (SWM) project and current ongoing projects were used. The required information included sewer network, radar-rainfall events, and flow monitoring data in order to develop model input and compare the results to the field data. SWMM4.99 and SWMM5 were used to run the model simulations. SWMM4.99 was customized based on SWMM 4.4H (OSU, 2004).

\subsubsection{Study Areas}

After reviewing the modeled sanitary areas, sewersheds with more reliable radar-rainfall events and corresponding flow monitoring records for the same time period were selected for consideration. From the approximate $257 \mathrm{mi}^{2}\left(666 \mathrm{~km}^{2}\right)$ of the entire SWM study area, an approximate 3,000-acre $(1,214$ ha) sanitary sewer area, which includes nine sanitary sewersheds, was selected for the analysis. The selected sanitary sewersheds are located in the East Branch Mill Creek sub-basin in Hamilton County, Ohio. The location of the selected sewersheds is shown in Figure 22.1, and the detailed and schematic sewer network in the selected sewersheds are shown in Figures 22.2 and 22.3. A total of nine flow monitoring stations were used in this study area. The outlet of the study area is at flow meter MC-EB-008, which is illustrated in Figure 22.2.

\subsubsection{Input Data}

The calibrated SWMM4 model inputs of each selected sewershed, obtained from the SWM project, were combined to create the model dataset for this study. The resulting dataset is made up of 1,212 pipes and 1,206 manholes.

A review of the radar-rainfall data and corresponding flow monitoring data was performed to identify appropriate rainfall events for this study using the following three criteria; (i) the availability of the rainfall and flow data, (ii) the quality of the flow monitoring data, and (iii) the level of system 
response indicated by the flow meters. After excluding the rainfall events that were used to calibrate models in SWM, the events of 03/04/2001, with total 0.4 -in $(1.02-\mathrm{cm})$ rainfall, and $04 / 11 / 2001$, with total 0.57 -in $(1.45-\mathrm{cm})$ rainfall, plus corresponding flow monitoring data were selected.

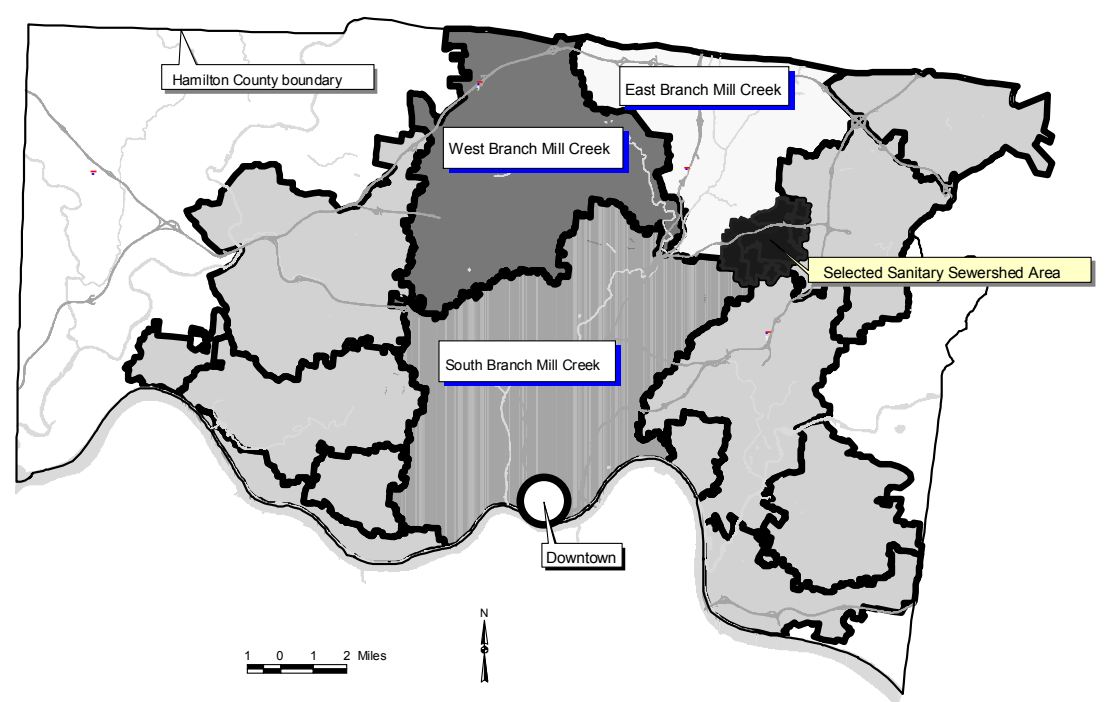

Figure 22.1 Location of the selected sanitary sewersheds used for this study.

The SWMM4 model dataset was converted to SWMM5 format and verification runs were performed for the selected rainfall events with both models. The hydrographs generated from both SWMM models at the nine outlets of the sewersheds, where the flow monitoring stations were located, were compared to the flow monitoring data. 


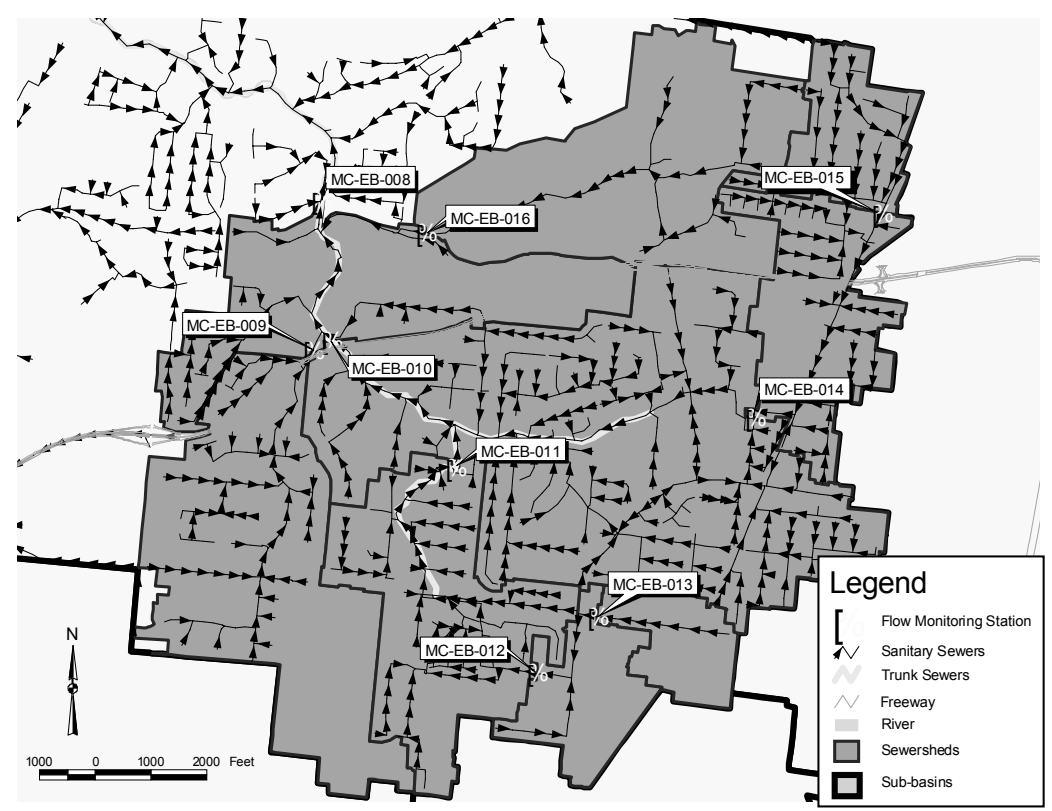

Figure 22.2 Sewer network in the selected sewersheds.

\subsection{Results and Discussions}

\subsubsection{Flow Pattern}

In general, the patterns of the simulated hydrographs from the two models matched each other, and also matched the pattern of field data at most flow meter locations in the sewersheds. In a few locations the simulated results were slightly different between models or the simulated results were slightly different from the observed data. Figures 22.4 to 22.11 provide the depth or flow hydrograph patterns of SWMM4 and SWMM5 compared to the flow meter data at the different outlets of the study area for the 3/4/2001 rainfall event and for the 4/11/2001 rainfall event, respectively. 


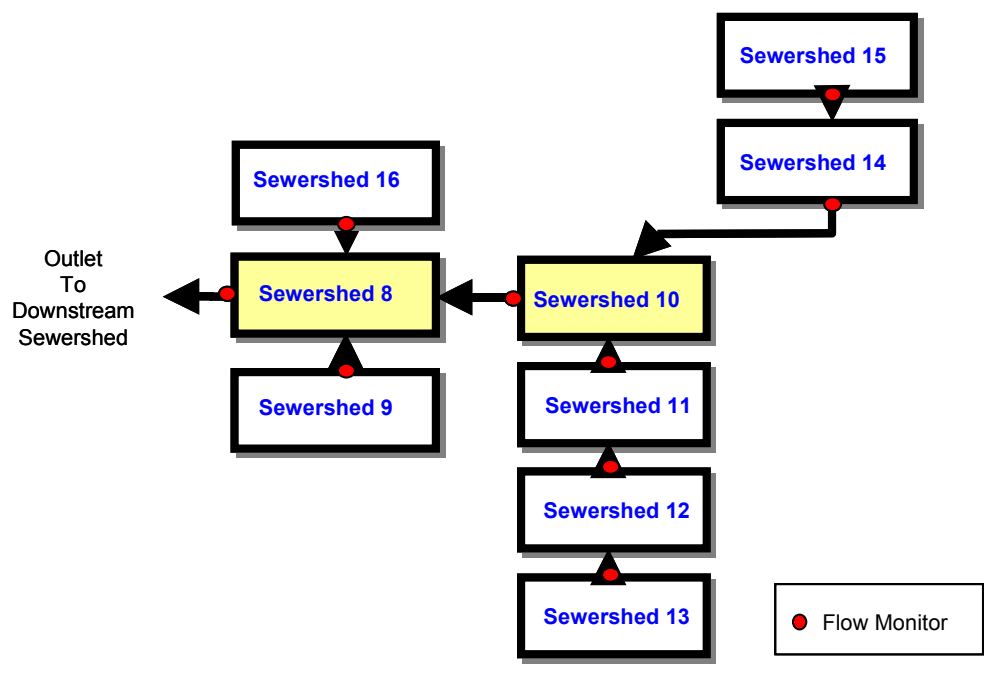

Figure 22.3 Schematic flowchart of the sewer network in the selected sewersheds.

\subsubsection{Peak Flow Rate/Depth}

The peak flow rates/depths generated from SWMM4 and SWMM5 were generally consistent with each other. For the 3/4/2001 event, the simulated results from both models had a difference of less than $5 \%$ in both the peak flow rate and depth at eight of the nine locations. The largest difference in the peak flow depth was $6 \%$ at the outlet of sewershed 10, with SWMM5 predicting a lower flow depth than SWMM4. For the 4/11/2001 event, the simulated peak flow rate from both models had a difference of less than $5 \%$ at eight of the nine locations, and the difference in the simulated peak depth from both models was less than $5 \%$ at seven locations. The largest difference in the peak flow rate was $34 \%$ at the outlet of sewershed 13, with SWMM4 over-predicting and SWMM5 under-predicting compared to the flow meter data. The largest difference in the simulated peak depth from both models was $20 \%$ at the outlet of sewershed 12 . 


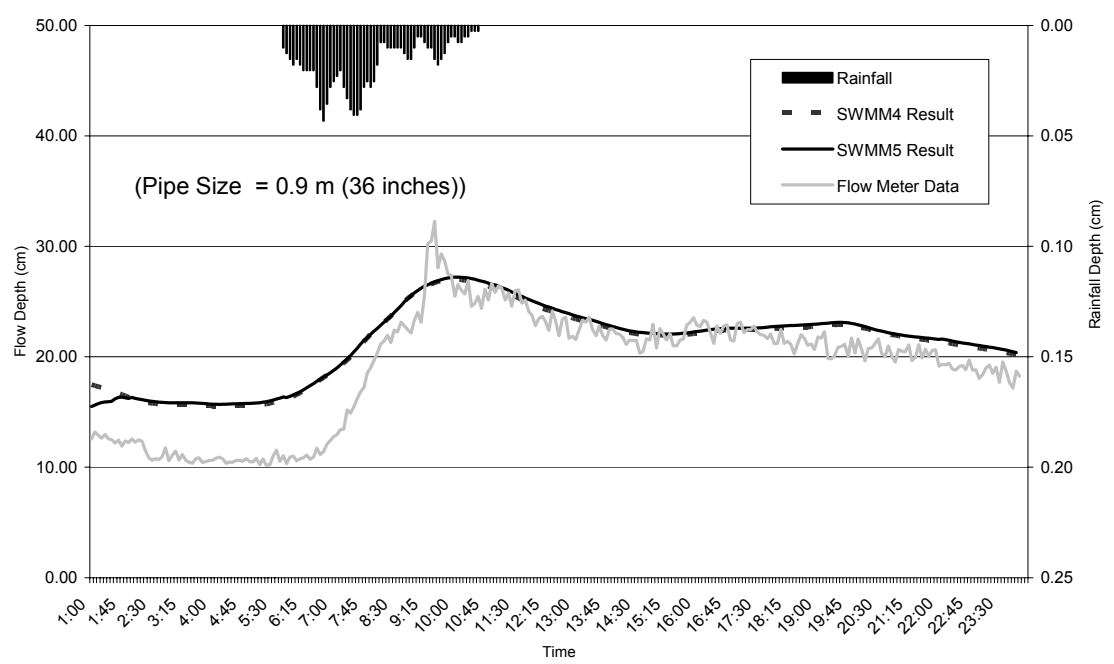

Figure 22.4 Depth hydrograph patterns generated from SWMM4 and SWMM5 at the outlet of Sewershed 8 compared to the flow data for the 3/4/2001 rainfall event.

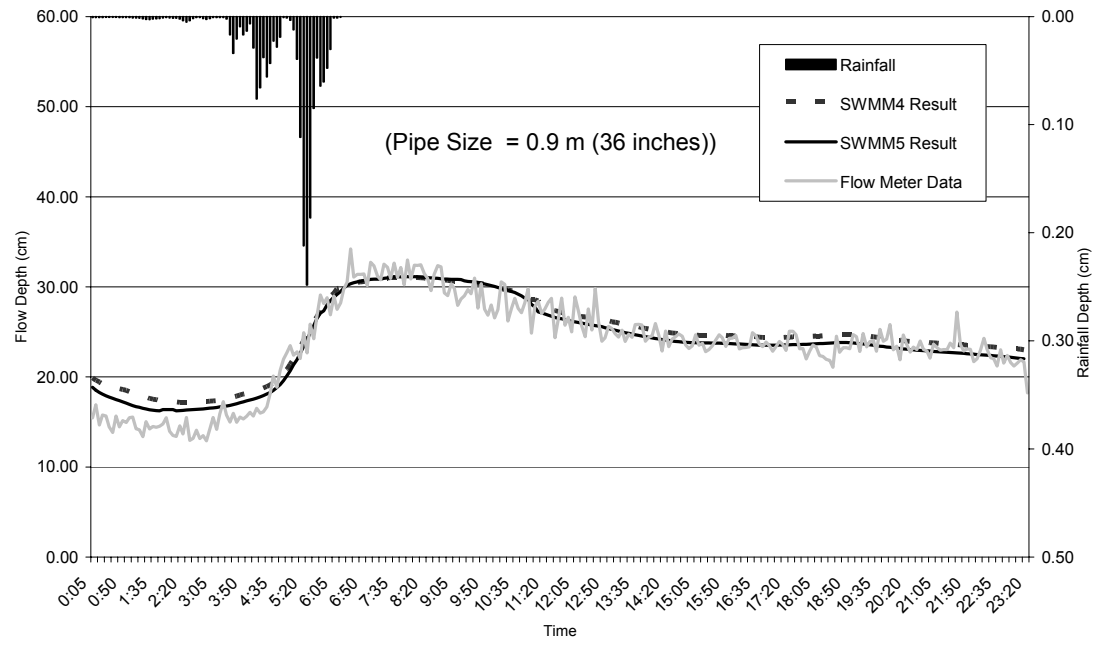

Figure 22.5 Depth hydrograph patterns generated from SWMM4 and SWMM5 at the outlet of Sewershed 8 compared to the flow data for the $4 / 11 / 2001$ rainfall event. 


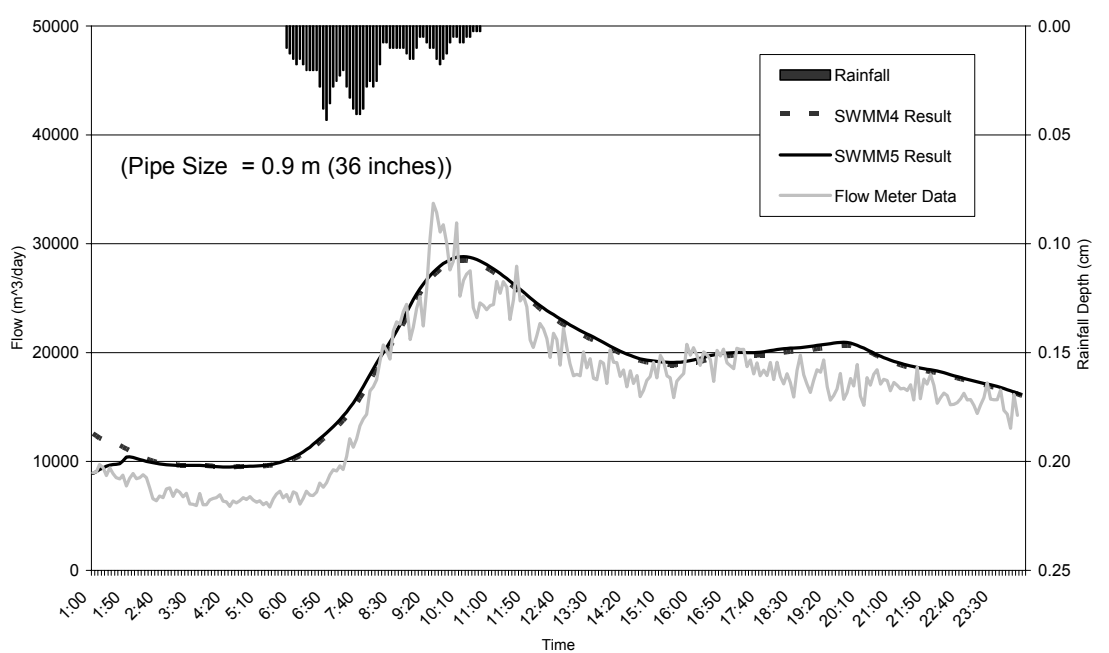

Figure 22.6 Flow hydrograph patterns generated from SWMM4 and SWMM5 at the outlet of Sewershed 8 compared to the flow data for the $3 / 4$ /2001 rainfall event.

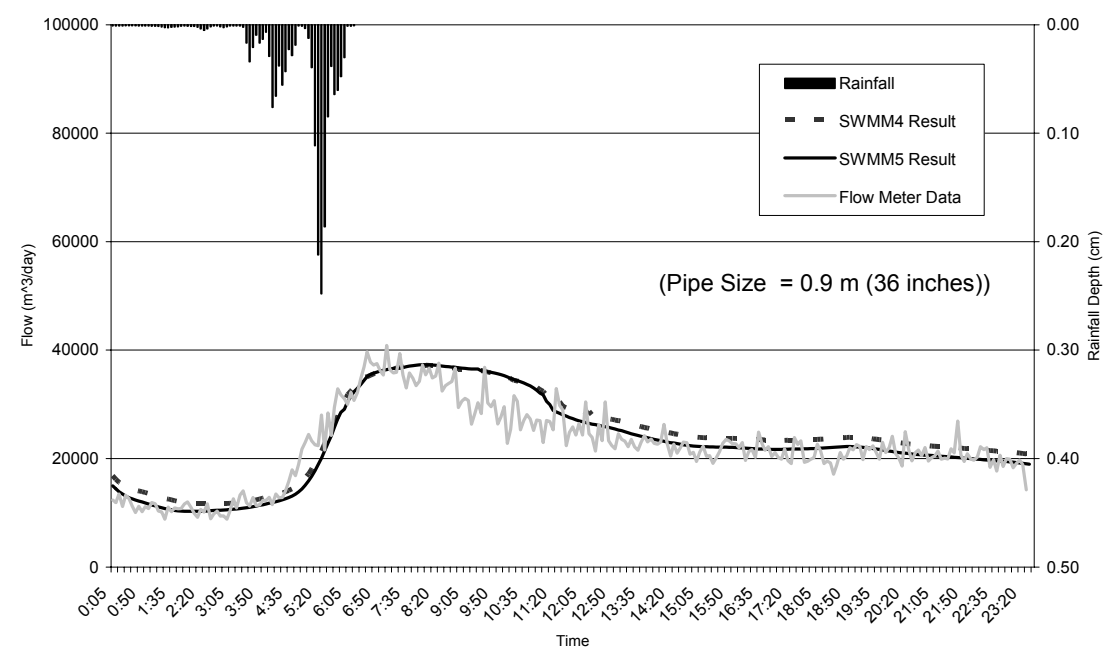

Figure 22.7 Flow hydrograph patterns generated from SWMM4 and SWMM5 at the outlet of Sewershed 8 compared to the flow data for the 4/11/2001 rainfall event. 


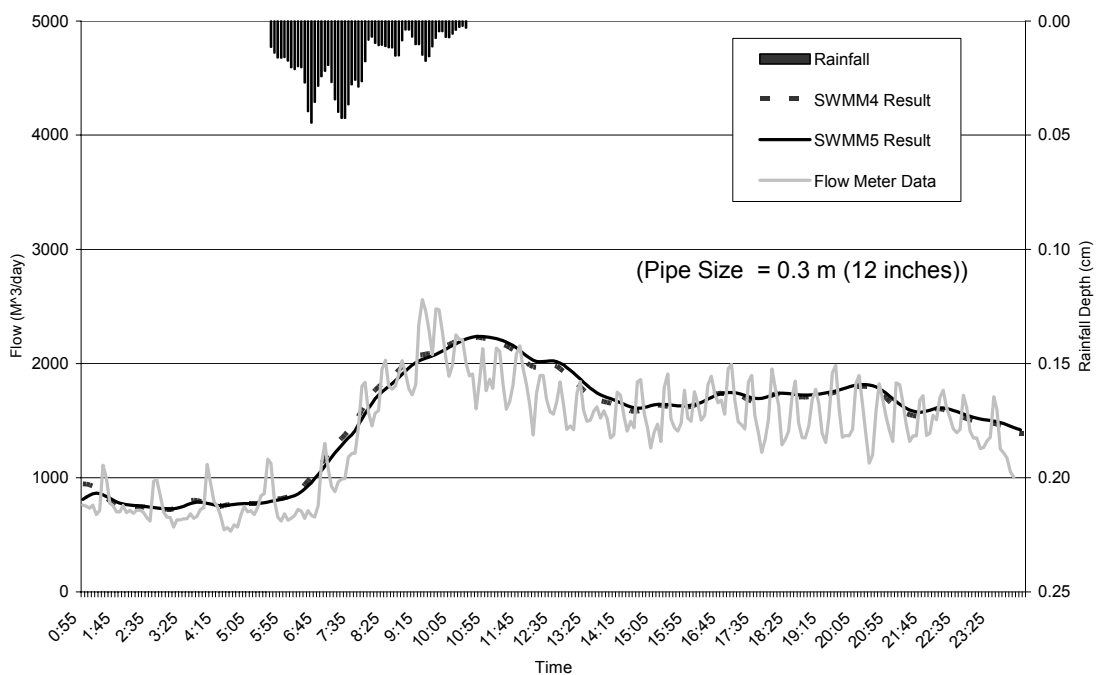

Figure 22.8 Flow hydrograph patterns generated from SWMM4 and SWMM5 at the outlet of Sewershed 9 compared to the flow data for the 3/4/2001 rainfall event.

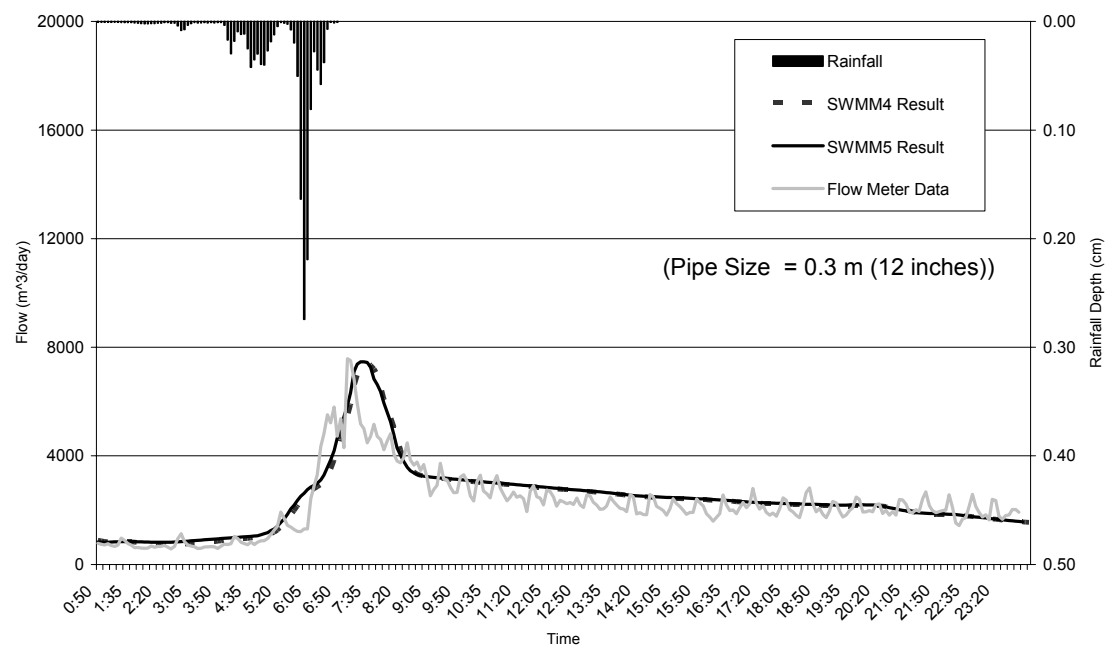

Figure 22.9 Flow hydrograph patterns generated from SWMM4 and SWMM5 at the outlet of Sewershed 9 compared to the flow data for the $4 / 11 / 2001$ rainfall event. 


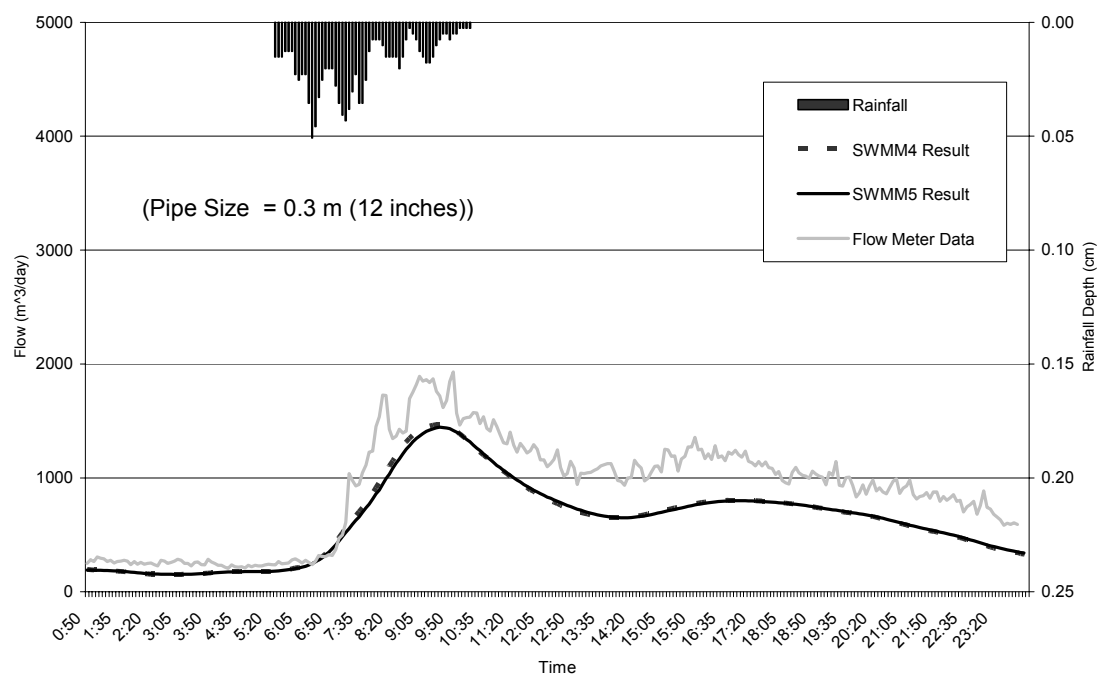

Figure 22.10 Flow hydrograph patterns generated from SWMM4 and SWMM5 at the outlet of Sewershed 13 compared to the flow data for the $3 / 4 / 2001$ rainfall event.

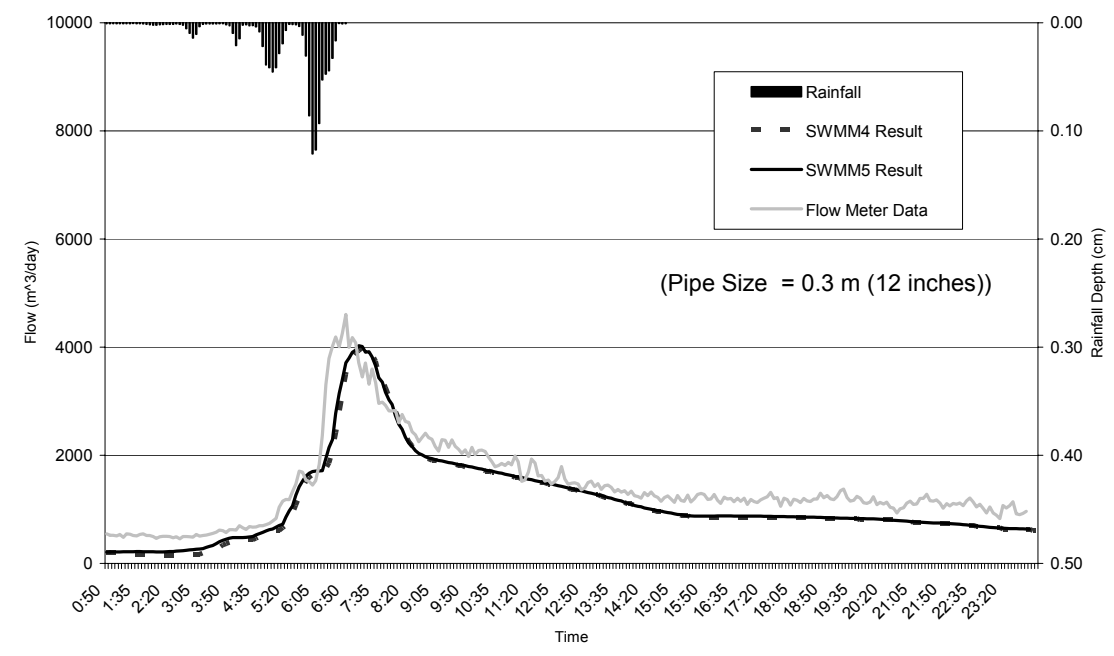

Figure 22.11 Flow hydrograph patterns generated from SWMM4 and SWMM5 at the outlet of Sewershed 13 compared to the flow data for the 4/11/2001 rainfall event. 
Compared to the observed flow data, however, both models underestimated flow rates and depths at most locations for the 3/4/2001 event. The average difference in the flow rate was $-21 \%$ for SWMM 4 and $-20 \%$ for SWMM5. The average difference in the flow depth was $-8 \%$ for both models. The largest discrepancy between the simulated and the observed flow rate for the $3 / 4 / 2001$ event was $-58 \%$ with SWMM4 and $-59 \%$ with SWMM5, both at sewershed 11. However, this sewershed was known to have estimated I/I parameters adopted from the adjacent sewershed in the model, which could explain the discrepancy between the simulated results and the observed data. For the 4/11/2001 event, the average difference between model predictions and data in terms of the flow rate was minor; only 2\% for SWMM4 and 3\% for SWMM5. The average difference in terms of the flow depth was $19 \%$ and $17 \%$ for SWMM4 and SWMM 5, respectively. Significant over-estimates were limited to sewershed 16 and sewershed 13. The difference for sewershed 16 can be attributed to estimated I/I parameters in the model (as for sewershed 11 above). However, the reasons for the large over-estimate of flow depth at sewershed 13 were unclear and need to be further investigated. Tables 22.1 and 22.2 show predicted results from both models, along with measured data at each flow meter location for the two rainfall events.

Table 22.1 Simulated peak flow rate/depth vs measured peak flow rate/depth at 3/4/2001 rainfall event.

\begin{tabular}{|c|c|c|c|c|c|c|c|c|c|c|c|}
\hline \multirow[b]{2}{*}{$\begin{array}{l}\text { Sewershed } \\
\text { Outlet }\end{array}$} & \multicolumn{3}{|c|}{ SWMM4 Result } & \multicolumn{3}{|c|}{ SWMM5 Result } & \multicolumn{3}{|c|}{ Flow Meter Data } & \multicolumn{2}{|c|}{ Rainfall } \\
\hline & $1 *$ & $2^{*}$ & $3^{*}$ & $1^{*}$ & $2^{*}$ & $3^{*}$ & $1^{*}$ & $2^{*}$ & $3 *$ & $4 *$ & $5^{*}$ \\
\hline EB-8 & 28482 & 0.27 & $9: 55$ & 28880 & 0.27 & 10:05 & 33724 & 0.32 & $9: 30$ & 0.04 & $6: 30$ \\
\hline EB-9 & 2233 & 0.07 & $10: 20$ & 2238 & 0.07 & 10:20 & 2574 & 0.08 & $9: 40$ & 0.05 & $6: 30$ \\
\hline EB-10 & 18081 & 0.45 & $9: 55$ & 18319 & 0.42 & 10:00 & 22067 & 0.51 & $9: 30$ & 0.04 & $6: 25$ \\
\hline EB-11 & 5673 & 0.14 & $9: 30$ & 5715 & 0.13 & $9: 45$ & 13740 & 0.16 & $9: 25$ & 0.04 & $7: 15$ \\
\hline EB-12 & 3537 & 0.22 & $8: 55$ & 3558 & 0.22 & $9: 15$ & 3671 & 0.20 & 9:20 & 0.05 & $6: 25$ \\
\hline EB-13 & 1468 & 0.17 & $9: 20$ & 1514 & 0.17 & $9: 30$ & 2385 & 0.20 & 9:05 & 0.05 & $6: 25$ \\
\hline EB-14 & 4014 & 0.12 & 10:00 & 4050 & 0.13 & 10:15 & 5413 & 0.14 & $10: 30$ & 0.05 & $7: 15$ \\
\hline EB-15 & 1512 & 0.10 & $9: 30$ & 1514 & 0.10 & $9: 45$ & 1779 & 0.13 & 9:50 & 0.05 & $7: 20$ \\
\hline EB-16 & 3268 & 0.13 & $9: 50$ & 3331 & 0.13 & 10:00 & 3293 & 0.11 & $13: 25$ & 0.04 & $7: 20$ \\
\hline
\end{tabular}
(cm); 5 - Time (hr:min) 
Table 22.2 Simulated peak flow rate/depth vs measured peak flow rate/depth at 4/11/2001 rainfall event.

\begin{tabular}{cccccccccccc}
\hline & \multicolumn{2}{c}{ SWMM4 Result } & \multicolumn{2}{c}{ SWMM5 Result } & \multicolumn{2}{c}{ Flow Meter Data } & \multicolumn{2}{c}{ Rainfall } \\
\hline $\begin{array}{c}\text { Sewershed } \\
\text { Outlet }\end{array}$ & $1^{*}$ & $2 *$ & $3^{*}$ & $1^{*}$ & $2 *$ & $3^{*}$ & $1^{*}$ & $2^{*}$ & $3^{*}$ & $4^{*}$ & $5^{*}$ \\
EB-8 & 37213 & 0.31 & $8: 20$ & 37320 & 0.31 & $8: 30$ & 40878 & 0.34 & $7: 10$ & 0.25 & $6: 00$ \\
EB-9 & 7432 & 0.12 & $7: 25$ & 7456 & 0.12 & $7: 25$ & 7570 & 0.16 & $7: 05$ & 0.27 & $6: 00$ \\
EB-10 & 34767 & 2.35 & $7: 20$ & 35390 & 2.35 & $7: 45$ & 36260 & 2.54 & $7: 35$ & 0.18 & $6: 00$ \\
EB-11 & 13469 & 0.24 & $7: 30$ & 13588 & 0.22 & $7: 35$ & 12339 & 0.20 & $7: 10$ & 0.21 & $6: 00$ \\
EB-12 & 6874 & 0.63 & $7: 05$ & 6586 & 0.50 & $6: 50$ & 8138 & 0.74 & $6: 50$ & 0.13 & $6: 00$ \\
EB-13 & 3974 & 0.36 & $7: 05$ & 4050 & 0.37 & $7: 10$ & 4618 & 0.15 & $6: 50$ & 0.12 & $6: 00$ \\
EB-14 & 11348 & 0.21 & $7: 35$ & 11431 & 0.22 & $7: 45$ & 12339 & 0.21 & $6: 30$ & 0.13 & $6: 05$ \\
EB-15 & 5054 & 0.19 & $7: 10$ & 5110 & 0.19 & $7: 20$ & 5034 & 0.21 & $6: 30$ & 0.15 & $6: 00$ \\
EB-16 & 4359 & 0.15 & $8: 20$ & 4391 & 0.15 & $8: 30$ & 2646 & 0.09 & $8: 20$ & 0.25 & $5: 55$ \\
\hline
\end{tabular}

Despite the occasional large discrepancies between model results and observed data at specific locations, a statistical analysis indicated that the results generated by both models showed similar trends as well as agreement on average with the observed data. The results of the statistical analyses for the 3/4/2001 rainfall event are shown in Figure 22.12 for peak depth and Table 22.3 for both peak depth and flow. Figure 22.13 (peak depth) and Table 22.4 (peak depth and flow) present the statistical results for the 4/20/2001 rainfall event. While a statistical analysis on such a small sample set cannot be considered conclusive, the general agreement between the two models, and between the models and data, is clearly supported by both the graphical comparisons and statistical parameters.

\subsubsection{Timing}

The times to peak predicted by both models generally agreed with each other; the simulated times to peak had a difference of less than $15 \mathrm{~min}$ at seven of nine locations for the 3/4/2001 rainfall event, and at eight of nine locations for the 4/11/2001 rainfall event. The largest difference between models in simulated time to peak was $25 \mathrm{~min}$ for the 3/4/2001 rainfall event and $40 \mathrm{~min}$ for the 4/11/2001 rainfall event. The location of both of these differences occurred at the outlet of sewershed 10 , in which the time to peak 
of the SWMM5 results had a slight delay and the SWMM4 results were slightly earlier compared to the flow meter data.

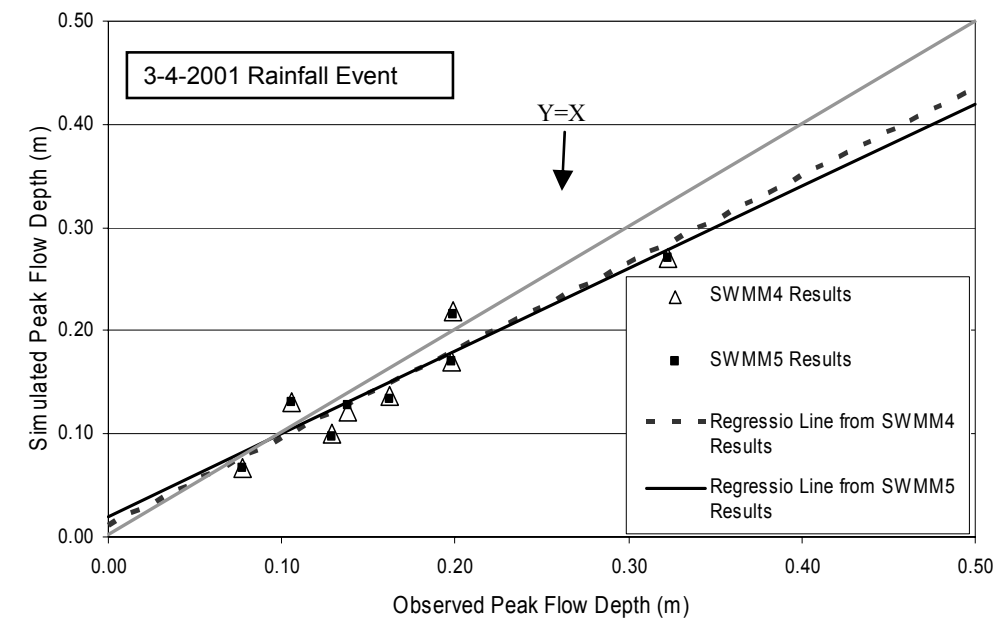

Figure 22.12 The simulated and observed peak depth for 3/4/2001 rainfall event.

Table 22.3 Linear regression summary of the simulated results and observed data for 3/4/2001 event.

\begin{tabular}{|c|c|c|c|c|}
\hline & \multicolumn{2}{|c|}{ Depth } & \multicolumn{2}{|c|}{ Flow } \\
\hline & $\begin{array}{l}\text { SWMM4 Results } \\
\text { vs. Flow Meter } \\
\text { (m) }\end{array}$ & $\begin{array}{l}\text { SWMM5 Results } \\
\text { vs. Flow Meter } \\
\text { (m) }\end{array}$ & $\begin{array}{l}\text { SWMM4 Results } \\
\text { vs. Flow Meter } \\
\left(\mathrm{m}^{\wedge} 3 / \text { day }\right)\end{array}$ & $\begin{array}{l}\text { SWMM5 Results } \\
\text { vs. Flow Meter } \\
\left(\mathrm{m}^{\wedge} 3 / \text { day }\right)\end{array}$ \\
\hline Linear Regression & $\mathrm{Y}=0.85 \mathrm{X}+0.01$ & $\mathrm{Y}=0.80 \mathrm{X}+0.02$ & $\mathrm{Y}=0.82 \mathrm{X}-442$ & $\mathrm{Y}=0.83 \mathrm{X}-460$ \\
\hline $\mathrm{R}^{\wedge} 2$ & 0.97 & 0.97 & 0.96 & 0.96 \\
\hline
\end{tabular}

Table 22.4 Linear regression summary of the simulated results and observed data for 4/11/2001 event.

\begin{tabular}{ccccc}
\hline & \multicolumn{2}{c}{ Depth } & \multicolumn{2}{c}{ Flow } \\
\hline & $\begin{array}{c}\text { SWMM4 Results } \\
\text { vs. Flow Meter } \\
(\mathrm{m})\end{array}$ & $\begin{array}{c}\text { SWMM5 Results } \\
\text { vs. Flow Meter } \\
(\mathrm{m})\end{array}$ & $\begin{array}{c}\text { SWMM4 Results } \\
\text { vs. Flow Meter } \\
\left(\mathrm{m}^{\wedge} 3 / \text { day }\right) \\
\mathrm{Y}=0.92 \mathrm{X}+629\end{array}$ & $\begin{array}{c}\text { SWMM5 Results } \\
\text { vs. Flow Meter } \\
\left(\mathrm{m}^{\wedge} 3 / \text { day }\right) \\
\mathrm{Y}=0.93 \mathrm{X}+576\end{array}$ \\
\hline $\mathrm{R}^{\wedge} 2$ & 0.99 & 0.98 & 0.99 & 0.99 \\
\hline
\end{tabular}




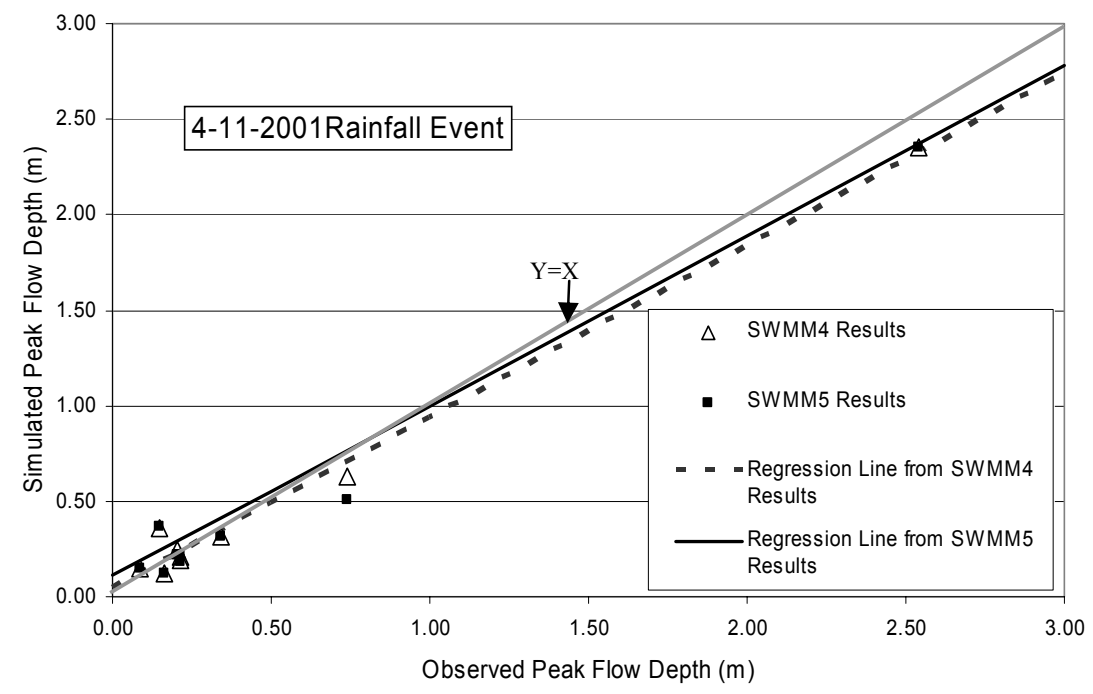

Figure 22.13 The simulated and observed peak depth for 4/11/2001 rainfall event.

Comparisons of the simulated times to peak from both models to the observed times to peak for the 3/4/2001 event indicated a reasonable match on average, and no systematic lag or acceleration (Figure 22.14). There is one outlier for this event evident in Figure 22.14; this outlier was discarded following review of the data (discussed below). For the 4/11/2001 event, there were consistent delays in time to peak exhibited by both models at most locations (Figure 22.15). Reviewing the 4/11/2001 radar-rainfall data revealed that (i) the regular gage station that was used to calibrate the radarrainfall data did not show the expected response, and (ii) the monitored wetweather flow arrived at the flow meter locations earlier than the rain was recorded at the gage station. These data discrepancies could cause bias in the calibrated radar-rainfall data and the time lag predicted in both models. For the entire system, there were less than 30 min differences in time to peak between the SWMM5 results and the observed data at six of nine locations for both rainfall events, while there were less than 30 min differences between the SWMM4 results and the observed data at six of nine locations for the 4/11/2001 rainfall event and at seven locations for the 3/4/2001 rainfall event. The simulated times to peak from both models had the largest difference compared to the flow meter data, a 40 min delay, at the outlet of 
sewershed 14 for the 3/4/2001 event. For the 4/11/2001 event, the simulated time to peak from both models had the largest difference compared to the flow meter data, slightly over an hour delay, at the outlet of sewershed 8 .

Figures 22.14 and 22.15 show all simulated times to peak at the nine sewershed outlets from both models against the observed times to peak. Figure 22.14 exhibits a pair of outlier data points that show a much earlier simulated time to peak than observed time to peak. These points represent the outlet of sewershed 16, and further study of the flow meter response at this location revealed that for this event, the flow meter response time was $6 \mathrm{~h} 5 \mathrm{~min}$ (i.e. the monitored peak flow arrived $6 \mathrm{~h} 5 \mathrm{~min}$ after the monitored peak rain). However, the average flow meter response time at 9 locations was $2 \mathrm{~h} 50 \mathrm{~min}$, while the second-largest observed response time was $3 \mathrm{~h} 15$ min. This evidence indicated that the flow meter response for the particular $3 / 4 / 2001$ event was in question.

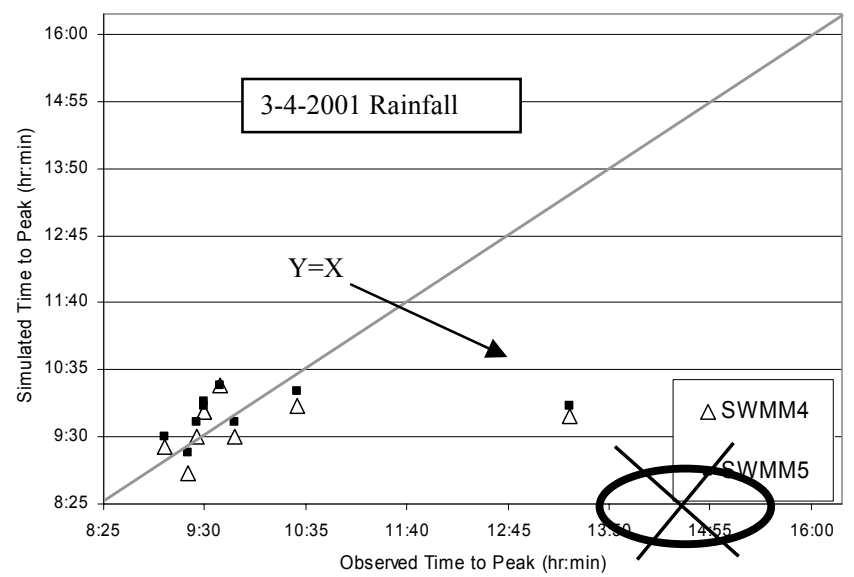

Figure 22.14 Simulated time to peak versus observed time to peak under 3/4/2001 rainfall event.

\subsection{Conclusions}

This study compared the simulated results from SWMM4.99 and SWMM5.0.005a against flow monitoring data at nine locations in the selected sanitary sewersheds in Cincinnati, Ohio. Calibrated SWMM4 model input data from a previous project were applied in both models. Both 
models were used to simulate two rainfall events that had not been used to calibrate the SWMM4 model. The model verification and comparison led to the following observations:

1. The simulated hydrograph patterns from both models matched the pattern of field data at most flow meter locations in the sewersheds.

2. The peak flow rates and depths predicted by SWMM4 and SWMM5 were consistent with each other. However, both models exhibited a tendency to under-estimate compared to the observed flow data.

3 . The times to peak from both SWMM models generally agreed with each other, with some minor differences. Both models predicted times to peak that had fairly good agreement with credible observed data, although the simulated results showed occasional time lags at a few locations.

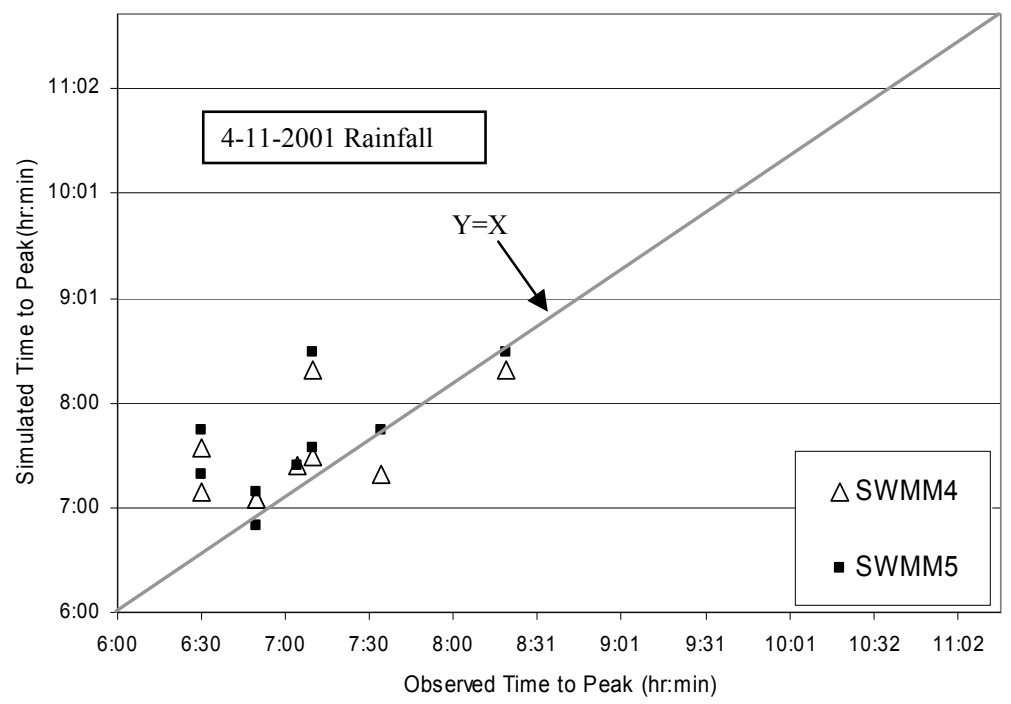

Figure 22.15 $\mathrm{S}$ imulated time to peak versus observed time to peak under 4/11/2001 rainfall event.

These observations indicate that both versions of SWMM can properly perform hydraulic and hydrological simulations for sanitary sewersheds. With significantly shorter run times (Chan et al., 2005), SWMM5 is able to provide comparable accuracy to that of SWMM4. Through the above discussions, it can be seen that there are three major factors that impact the ability of a model to match observed conditions - flow monitoring data, 
radar-rainfall data, and model performance. The reliability of all three factors should be considered in order to properly evaluate model results, because both model and observed (flow and rainfall) data are susceptible to errors. Therefore, it is important to obtain the largest possible observed dataset, and review the data carefully, before selecting calibration events.

This study focused on sanitary sewersheds and provided examples and comparisons of the relevant model results. In the future, the comparison of the results from combined sewersheds will be included to extend the study.

\section{References}

Chan, C.C., E. Burgess, T. Schade and R.E. Dickinson. 2004. "Design of the SWMM Data Translation and the Testing of SWMM 5 Engine." Journal of Water Management Modeling R220-17. doi: 10.14796/JWMM.R220-17.

Chan, C.C., R.E. Dickinson and E. Burgess. 2005. "Runtime Comparisons between SWMM 4 and SWMM 5 using Continuous Simulation Model Networks." Journal of Water Management Modeling R223-11. doi: 10.14796/JWMM.R223-11.

Huber, W. C. and R. E. Dickinson (1988). SWMM Version 4 User's Manual. US Environmental Protection Agency. Oregon State University, 2004. http://ccee.oregonstate.edu/swmm/\#VERSION\%204.4

Rossman, L., 2005. Storm water management model quality assurance report: dynamic wave flow routing, Water Supply and Water Resources Division, National Risk Management Research Laboratory, Cincinnati, OH 45268

SWMM5.0.005a, 2005. http://www.epa.gov/ednnrmrl/swmm/index.htm. 
